\title{
Assessment of antimycotic activity of seabuckthorn (Hippophae rhamnoides) leaf exacts against common fungi associated with skin dermatitis
}

\author{
Harshit Verma, Mandeep Sharma, Rajesh Chahota and Akanksha Palial \\ Department of Veterinary Microbiology \\ Dr. G.C. Negi College of Animal and Veterinary Sciences, CSK HPKV, Palampur, (H.P.), India \\ Corresponding author: Harshit Verma, email: dr_harshitverma@yahoo.co.in \\ Received:18-07-2012, Accepted: 11-08-2012, Published online: 30-01-2013
}

How to cite this article: Verma H, Sharma M, Chahota R and Palial A (2013) Assessment of antimycotic activity of seabuck thorn (Hippophae rhamnoides) leaf exacts against common fungi associated with skin dermatitis, Vet. World 6(4): 205-208, doi: 10.5455/vetworld.2013.205-208

\begin{abstract}
Aim: To study the antimycotic activity of seabuckthorn leaf extracts against common fungi associated with skin infection.

Materials and Methods: A total of 31 isolates were collected from the skin cases of animals and the leaves of seabuckthorn collected from the Lahaul and Spiti valley of the Himachal Pradesh. The extracts from the leaves were extracted according to standard procedures. Antimycotic activity was examined by employing agar disc diffusion method on Roswell Park Memorial Institute medium (RPMI). Different concentrations of leaf extracts i.e. $0.50 \%, 2 \%, 3 \%, 4 \%, 5 \%$, respectively were used.
\end{abstract}

Results: The study revealed that the inhibitory effect of SBT leaf extract at 5\% concentration was observed to be almost $80 \%$ in $12 \mathrm{hrs}$ of reading as compared to the standard drugs used as positive control against fungal isolates.

Conclusion: Plants are important source of potentially useful structures for the development of new chemotherapeutic agents. The first step towards this goal is the in vitro antimycotic activity assay. In the present study, a wide range of pathogenic microorganisms were recovered from the clinical samples, including bacteria and fungus. The seabuckthorn methanolic leaf extracts (hot and cold) were studied for their antimycotic activity against common fungal pathogens.

Keywords: antimycotic, disc diffusion, seabuckthorn leaf extract

\section{I ntroduction}

"Antimicrobial resistance is the global problem that needs urgent action" [1]. It is undiluted truth that pain, disease and death are always associated with the human and animal life. The humans of early ages used therapeutic agents available easily to them and thus, plants have been used as remedies since time immemorial. The plants are therefore, man's oldest resources of useful drugs. The history of the medicine and pharmacy begins with Hippocrates, the father of medicine. Medicinal herbs for the treatment of diseases have actively been practiced since the beginning of human civilizations. The skin is supposed as an organ of considerable elasticity and tensile strength that provides a barrier to the external environment. Its prime function is to prevent the invasion of bacteria and viruses and thus to maintain internal homeostasis. One of the major concerns in healthcare today is the ineffectiveness of antibiotics towards new and reemerging diseases due to the developed resistance in many pathogens. Thus, there is an urgent need to identify novel anti-microbial molecules as leads for effective drug development. Seabuckthorn (Hippophae species) is one among the widely known important medicinal plants. The genus name Hippophae is classical Latin for "shining horse," a name that was given in ancient times after it was found that feeding the leaves to horses improved their health and made their hair shiny. The plant has got tremendous potential for therapeutic utilization in human and Veterinary medicine, as it is reported to possess many bioactive substances notably lipids, fatty acids, vitamins (both fat soluble and water soluble), flavonoids, tannins, phenols, steroids, 5-hydroxytryptamine etc. [2]. The presence of these bioactive substances in the plant contributes enormously to its various properties like antibacterial, antifungal, immunostimulant, anti-inflammatory, antiradiation, antioxidant, hepatoprotective, cytoprotective, anticancerous, anti-artheroscle-rosis, anti-diabetic, anti-ulcer as well as wound healing actions [3].

In India, seabuckthorn is found in Himalayan states of Himachal Pradesh, Ladakh (J\&K), Uttranchal, Sikkim and Arunachal Pradesh. There are about 12,000 ha of seabuckthorn under thick forests, mainly in Ladakh. In Himachal Pradesh, seabuckthorn grows in Lahaul-Spiti, upper Kinnuar and Pangi in Chamba district. Both $H$. rhamnoides and $H$. Salicifolia have been found in Chango area of upper Kinnaur [4]. Seabuckthorn has also been found in high altitude areas of Shimla and Kullu districts. "India has world's second largest resource of seabuckthorn. Natural products will always be considered as one of the major sources of new drugs in the future because it offers structural diversity, and most are small in size. Some experts believe that plants may well hold the secret to combat diabetes, cancer and AIDS etc. The Hiporamin a tannin fraction from SBT possessing a wide spectrum of antiviral activities and mild antimicrobial activities [5]. 
The present study was carried out to determine the in vitro antimycotic activity of methanolic extracts of seabuckthorn leaves against common fungal pathogens associated with skin dermatitis [6].

\section{Materials and Methods}

Plant material: The seabuckthorn leaves were collected from the Lahaul and Spiti valley of the Himachal Pradesh. The leaves were than shade dried and then brought to the Department of Veterinary Microbiology, DGCN COVAS, Palampur.

Fungal cultures: The standard strains of Microsporum gypseum and Trichophyton rubrum were obtained from the Institute of Microbial Technology, Chandigarh (IMTECH). In addition, clinical isolates of Microsporoum gypsum, Trichophyton rubrum, Aspergillus spp., Mucor spp. Microsporum canis, Candida spp., Rhizopus spp. and Absidia spp. were isolated from clinical cases of skin and wound infections from Veterinary Clinic, College of Veterinary and Animal Sciences, Palampur, H.P.

Identification of fungi: Identification of fungi was done on the basis of macroscopic and microscopic morphology/characteristics.

Macroscopic morphology: Textures, topography, growth rate, obverse and reverse side pigmentation of colonies were noted.

Microscopic characteristics: Microscopic characteristic of fungi e.g. budding cells, hyphal structures, macroconidia, microconidia and other mycotic structures were examined.

Drug sensitivity profile of fungal isolates: Drug sensitivity of fungal isolates was observed by disc diffusion method as recommended by the NCCLS (M38-A standard) [7]. The fungal isolates after identification were subjected to in-vitro antifungal susceptibility testing by disc diffusion methods. The fungal isolates were grown on PDA slants for one week at $35^{\circ} \mathrm{C}$ and then flooded with approximately $1 \mathrm{ml}$ of sterile NSS. The resultant liquid was allowed to stand in a test tube to allow the heavier particles to settle down. The supernatant was taken out and mixed for 10 min. and the opacity adjusted to $0.4 \mathrm{McFarland}$ barium sulfate opacity standards. A sterile swab was used to streak the liquid on to the RPMI agar plates. Antifungal discs were placed on the agar and plates were incubated at $35^{\circ} \mathrm{C}$. Results were interpreted $24 \mathrm{hrs}$ and $48 \mathrm{hrs}$. Antifungal discs and their concentration have been shown in Table-1.

Protocol for inoculums preparation for fungus: Inoculums consists of non-germinated conidial suspension

Step 1: Growing of fungus on potato dextrose agar slants 7 days at $35^{\circ} \mathrm{C}$

Step 2: Flooding of slant with approximately $1 \mathrm{ml}$ of sterile NSS and subsequently withdrawal of suspension Step 3: Heavy particles allowed settling for 3 to $5 \mathrm{~min}$
Step 4: Upper suspension of non-germinated condia/ sporangiospores/hyphal fragments mixed for 15 seconds

Step 5: Turbidity measured at $530 \mathrm{~nm}$

Step 6:: Diluted 1:50 in RPMI 1640 medium

Table-1. Antifungal discs used and their concentration

\begin{tabular}{lll}
\hline Antifungal agents & Symbol & Conc./disc \\
\hline Ketoconazole & $\mathrm{Kt}$ & $10 \mu \mathrm{g}$ \\
Miconazole & $\mathrm{Mi}$ & $10 \mu \mathrm{g}$ \\
Nystatin & $\mathrm{Ns}$ & $100 \mathrm{units}$ \\
Amphotericin-B & $\mathrm{Ap}$ & $100 \mathrm{units}$ \\
Itraconazole & $\mathrm{It}$ & $10 \mu \mathrm{g}$ \\
Fluconazole & $\mathrm{Fu}$ & $10 \mu \mathrm{g}$ \\
Clotrimazole & $\mathrm{Cc}$ & $10 \mu \mathrm{g}$ \\
\hline
\end{tabular}

\section{Preparation of leaf extract}

Grinding of selected plant material: After drying of leaves at $37^{\circ} \mathrm{C}$ for 3 to 5 days, there were grounded in the grinding machine made for the laboratory. Exposure to sunlight was avoided to prevent the loss of active compounds [8].

Extraction methods: In this study, we used two protocols of extraction: Soxlet extraction and Cold percolation.

Soxlet extraction method: A thimble was prepared by using whatman filter paper. $30 \mathrm{gm}$ of dried powder of seabuckthorn leaves was kept in thimble for extraction. $400 \mathrm{ml}$ of 100 per cent of methanol was used for this process and left for 8 hours in soxlet apparatus at $60^{\circ} \mathrm{C}$. Filtered the residue by using whatman filter paper no. 1 . The extracted liquid was subjected to rota-evaporation or water bath evaporation to remove the excess of methanol. The semi solid extract produced was kept in the deep freezer at $-80^{\circ} \mathrm{C}$ overnight.

Cold extraction method: 100 gm of seabuckthorn leaves powder was mixed with $400 \mathrm{ml}$ of 100 per cent methanol and left for 24 hours in orbital shaker at 25 to $30^{\circ} \mathrm{C}$ at $120 \mathrm{rpm}$. Filtered the residue by using triple whatman filter paper no.1. Dried the filtrate by the rotator vaccume pressure for recovery of methanol. The semi solid extract produced was kept in the deep freezer at $-80^{\circ} \mathrm{C}$ overnight.

\section{Result and Discussion}

I solation pattern in fungal dermatitis: Microsporum gypseum was major fungus isolated (16.13\%) followed by Aspergillus spp. (16.13\%). Dermatophytes accounted for 36.00 per cent of the total fungal isolates. Other molds and yeasts accounted for 64.00 per cent. Isolation pattern has been shown in Table-2. Other dermatophytes isolated were Microsporum canis (9.67\%), Trichophyton rubrum (6.45\%), Epidermatophytonflocossum (3.23\%). Among non-dermatophytes Aspergillus species and Mucor spp. were the more frequently isolated fungi with prevalence of $16.13 \%$ and $12.9 \%$, respectively. Other fungi isolated were Rhizopus spp. (9.67\%), Candida spp. (16.13\%), Absidia spp. (9.67\%), respectively. 
Table-2. I solation pattern in fungal dermatitis

\begin{tabular}{lcc}
\hline Organism isolated & No. of isolates & Percent isolates \\
\hline Aspergillus spp. & 5 & 16.13 \\
Mucor spp. & 4 & 12.9 \\
Microsporum gypseum & 5 & 16.13 \\
Microsporum canis & 3 & 9.67 \\
Trichophyton rubrum & 2 & 6.45 \\
E pidermophton flocossum & 1 & 3.23 \\
Candida spp. & 5 & 16.13 \\
Rhizopus spp. & 3 & 9.67 \\
Absidia spp. & 3 & 9.67 \\
Total & 31 & 100 \\
\hline
\end{tabular}

Plants are important source of potentially useful structures for the development of new chemotherapeutic agents. The first step towards this goal is the in vitro antimycotic activity assay [9]. In the present study, a wide range of fungal isolates were recovered from the clinical samples, including dermatophytes and other zygomycetes. The seabuckthorn methanolic leaf extracts (hot and cold) were studied for their antimycotic activity against common skin dermatophytes. These included 31 fungal isolates. Both SBT leaf extracts (hot and cold) showed significant antimycotic activity against the common fungal isolates. The antifungal activity of SBT leaf extracts (Hot and Cold) against skinborne fungi is presented in Table- 3 and 4 as zone of inhibition (in mm). Antimycotic activity of leaf extracts were tested with a comparable concentration of antibiotics ranging 10 to $30 \mu \mathrm{g} /$ disc. The leaf extract was found significantly effective against $M$. gypseum and $T$. rubrum. The inhibitory effect of SBT leaf extracts at 5 per cent concentration was observed to be almost 50 per cent compared to the standard drugs used as positive control against $M$. gypseum and T. rubrum
(Table 3, 4 and Fig. 1, 2). The cold methanolic extract was found to be most significant as compared to the hot methanolic extract. Cold methanolic extract at 5 per cent concentration was giving $10.13 \mathrm{~mm}$ zone of inhibition against $M$. gypseum and $T$. rubrum while hot was almost giving $9 \mathrm{~mm}$ zone of inhibition. Many reports reveled, that plant metabolites appear to be one of the better alternatives as they are known to have minimal environmental impact [10]. Hence, the plants can be used to discover bioactive natural products that may serve as leads in the development of new pharmaceuticals research activities [11]. In 2010 Sule [12] the in vitro investigation of ethanolic activities of extracts of Senna alata leaf was carried on Dermatophytes which include the genera Trichophyton, Microsporum and Epidermatophyton and their results showed that the leaf exuadates and the ethanolic extract of the leaf of Senna alata L. Exhil: had marked antifungal effects on Microsoprum canis, Trichophyton mentagrophytes and Epidermatophyton spp. The ethanolic extract showed the highest zone of inhibition on Trichyophton spp. and Epidermatophyton spp. 20.50 and $20.00 \mathrm{~mm}$ zone of inhibition, respectively.

\section{Conclusion}

In this study, the extract of seabuckthorn leaves extract having high potential of antimycotic activity. It showed varying degrees of activities against all the tested dermatophytes with better antifungal activity against $M$. gypseum and T. rubrum. The phytochemical studied revealed the presence of important secondary metabolites (alkaloids, saponin, tannin and steroids), thusindicating the therapeutic potential of seabuckthorn leaf.

Table-3. In-vitro antimycotic activity with hot methanolic extract indicating the zone of inhibition in $\mathrm{mm}$ (Mean \pm S.E.)

\begin{tabular}{|c|c|c|c|c|c|c|c|c|}
\hline \multirow[t]{2}{*}{ S.No. } & \multirow[t]{2}{*}{ Genus spp. } & \multirow[t]{2}{*}{ Positive control } & \multicolumn{5}{|c|}{ Concentration of leaf extract } & \multirow[t]{2}{*}{ Negative control } \\
\hline & & & $0.5 \%$ & $2 \%$ & $3 \%$ & $4 \%$ & $5 \%$ & \\
\hline 1. & M. gypseum & $12.9 \pm 0.4819$ & $5.5 \pm 0.4014$ & $7.9 \pm 0.2769$ & $8.6 \pm 0.1633$ & $8.9 \pm 0.2333$ & $9.8 \pm 0.2000$ & Resistant \\
\hline 2. & 1. rubrum & $10.75 \pm 0.3134$ & $5.36 \pm 0.3239$ & $7.5 \pm 0.2673$ & $8.37 \pm 0.1830$ & $8.63 \pm 0.1830$ & $9.63 \pm 0.1830$ & Resistant \\
\hline
\end{tabular}

Table-4. In-vitro antimycotic activity with cold methanolic extract indicating the zone of inhibition in $\mathrm{mm}$ (Mean \pm S.E.)

\begin{tabular}{|c|c|c|c|c|c|c|c|c|}
\hline \multirow[t]{2}{*}{ S.No. } & \multirow[t]{2}{*}{ Genus spp. } & \multirow[t]{2}{*}{ Positive control } & \multicolumn{5}{|c|}{ Concentration of leaf extract } & \multirow[t]{2}{*}{ Negative control } \\
\hline & & & $0.5 \%$ & $2 \%$ & $3 \%$ & $4 \%$ & $5 \%$ & \\
\hline 1. & M. gypseum & $10.7 \pm 0.2134$ & $5.5 \pm 0.3266$ & $7.9 \pm 0.1795$ & $8.6 \pm 0.1633$ & $9.7 \pm 0.1528$ & $10.6 \pm 0.1633$ & Resistant \\
\hline 2. & T. rubrum & $11.0 \pm 0.2673$ & $4.75 \pm 0.2500$ & $7.38 \pm 0.1830$ & $8.0 \pm 0.1890$ & $9.38 \pm 0.1830$ & $10.13 \pm 0.2266$ & Resistant \\
\hline
\end{tabular}

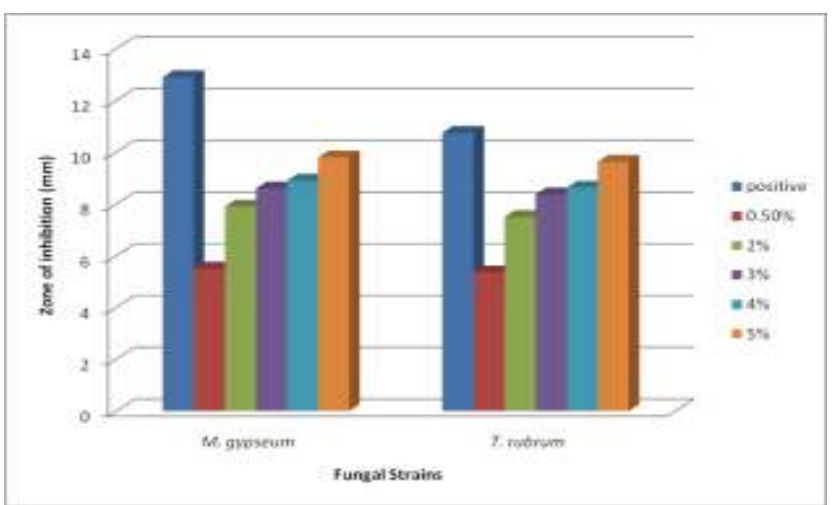

Fig. 1. In-vitro antimycotic activity with SBT leaves hot methanolic extract

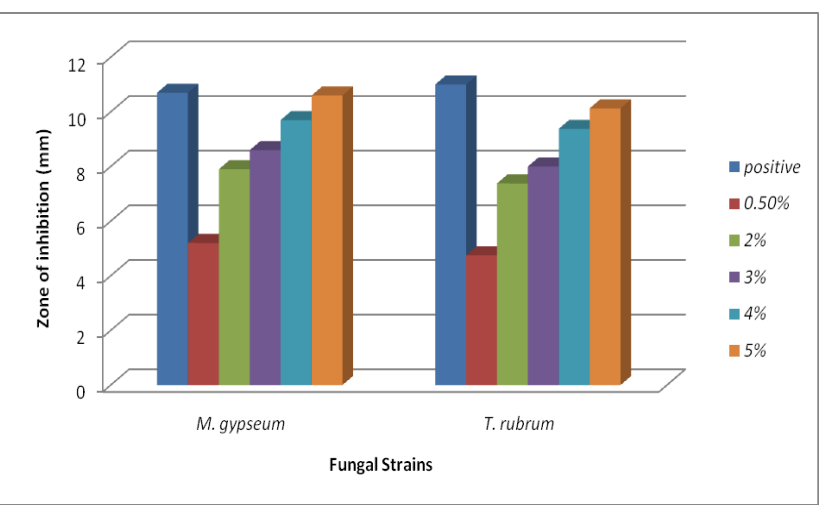

Fig. 2. . In-vitro antimycotic activity with SBT leaves cold methanolic extract 
It showed the presence of bioactive compounds as well as the antifungal properties of methanolic extracts. However, this finding provides an insight into the usage of this plant in treatment of fungal infections.

\section{Authors' contribution}

MS designed the study and all the other authors performed research experiments. MS drafted and revised the manuscript. All the authors read and approved the final manuscript.

\section{Acknowledgements}

Authors are thankful to the Dean, College of Veterinary and Animal Sciences, Palampur (H.P.) for providing laboratory facilities.

\section{Competing interests}

Authors declare that they have no competing interest.

\section{References}

1. http://www.who.int/csr/resources/publications/drugresist/ en/EGlobal_Strat.pdf. Retrieved on 01-07-2012.

2. Risto E. and Baoru Y. (2003) Seabuckthorn oils: Towards health mucous membrane. Agro Food Industry Hi-tech: 5357.

3. Mingyu X., Xiaoxuan S. and Jinhua C. (2001) The medicinal research on seabuckthron. In: Proceedings International Workshop on Seabuckthron. 18-21.

4. Singh V. (1995) Rooting rates of hardwood cuttings of seabuckthorn (Hippophae rhamnoides). Journal of Tree Science 14(2): 87-88.

5. Shipulina L.D., Tolkachev O.N., Krepkova L.V., Bortnikova
V.V. and Shkarenkov A.A. (2006) Anti-viral, anti microbial and toxicological studies on seabuckthorn (Hippophae rhamnoides L.). Seabuckthorn (Hippophae L.) - A multipurpose wonder plant Vol-II. Biochemistry and pharmacology. 471-483.

6. Singh V. (2003) Performance of some exotic forms of seabuckthorn (Hippophae L.) in dry temperate Himalayas, India. In: Seabuckthorn -A Resource of Health, a challenge to Modern technology. Proceedings of Ist Congress of the International Seabuckthorn Association Berlin, Germany, $214 \mathrm{p}$.

7. Sharma Vikas. (2009)Investigation on the various etiological agents of canine dermatitis with special emphasis on fungal pathogens. MVSc Thesis, submitted to COVAS, Palampur H.P.

8. Osman Erkmen and Mehmet Musa Özcan. (2008) Antimicrobial Effects of Turkish Propolis, Pollen, and Laurel on Spoilage and Pathogenic Food-Related Microorganisms. Journal of Medicinal Food. 11(3): 587592.

9. Mohannad G and Saghir A.L. (2009) Antibacterial Assay of Cinnamomum cassia (Nees and Th. Nees) Nees ex Blume Bark and Thymus vulgaris L. Leaf Extracts against Five Pathogens. Journal of Biological Sciences. 9:280-282.

10. Pawar B.T. (2011) Antifungal activity of some leaf extracts against seed-borne pathogenic fungi. International Multidisciplinary Research Journal. 1/4:11-13.

11. Bhalodia N. R. and Shukla V. J. (2011) Antibacterial and antifungal activities from leaf extracts of Cassia fistula 1.: An ethnomedicinal plant. J Adv Pharm Technol Res. 2(2):104109.

12. Sule W.F., Okonko I.O., Joseph T.A., Ojezele M.O., Nwanze J.C., Alli J.A., Adenale O.G. and Ojezele O.J. (2010) In vitro antifungal activity of Senna alata Linn. Crude leaf extract. Research Journal of Biological Science 5(3):275-284.

$* * * * * * * *$ 